\title{
Can HIV infection during pregnancy cause an intrauterine growth restriction?
}

\author{
Simona Claudia Cambrea ${ }^{1,2^{*}}$, Doina Eugenia Tănase ${ }^{1}$, Maria Margareta llie', Simona Diaconu', Consuela Marcaş ${ }^{1}$, \\ Dalia Sorina Carp ${ }^{1}$, Stela Halichidis ${ }^{1,2}$, Lucian Cristian Petcu ${ }^{2}$ \\ From The 9th Edition of the Scientific Days of the National Institute for Infectious Diseases Prof Dr Matei Bals \\ Bucharest, Romania. 23-25 October 2013
}

\section{Background}

Intrauterine growth restriction (IUGR) indicates the presence of a pathophysiological process occurring in utero that inhibits fetal growth. IUGR has been associated with increased perinatal and infant mortality. There are many maternal factors responsible for IUGR. Some studies have suggested that HIV infection could increase the risk of IUGR. Specifically, in IUGR, the baby's estimated weight is below the 10th percentile. The objective of this study was to evaluate the proportion of children born to HIV positive women who presented IUGR.

\section{Methods}

We performed a retrospective study on the relevant parameters in newborns and mothers: demographic data, duration and type of combined antiretroviral treatment (cART). We analyzed anthropometric data of the newborn: weight, length, cranial circumference, and Apgar score. Statistical analysis was performed using MedCalc Software 2013.

\section{Results}

Over a period of 5 years and 8 months, 124 newborn to 97 $\mathrm{HIV}+$ mothers have been monitored. The median age in mothers was 22 (95\%CI: 22-23), and mean 22.8 (range: 17 to 39). The mean Apgar score in newborns was 8.54 (range: 4 to 10), and median 9. The mean birth weight in newborns was $2670 \mathrm{~g}$ (range: 1000 to 3900), and median $2700 \mathrm{~g}$. The proportion of children with birth weight less than 10 th percentile was $58.05 \%$. The mean length was $47.5 \mathrm{~cm}$ (range: 40 to 57 ), with a proportion of children below the 10th percentile of $29.26 \%$. Infants who presented below the 10th percentile for weight and length were
$22.76 \%$. About $11.38 \%$ of infants were below the 10 th percentile for weight, length and cranial circumference. 97.5\% of children received cART after birth, and $93.1 \%$ of mothers received cART during pregnancy. In the studied period the mortality rate was $5.6 \%$ in children and $7.2 \%$ in mothers.

\section{Conclusion}

More than half $(58.53 \%)$ of the infants born to HIV positive mothers were small for gestational age. $22.76 \%$ of infants were with IUGR, and $11.38 \%$ of them presented symmetrical IUGR.

\section{Authors' details}

${ }^{1}$ Clinical Infectious Diseases Hospital of Constanța, Romania. ${ }^{2}$ Faculty of Medicine, "Ovidius" University, Constanța, Romania.

Published: 16 December 2013

doi:10.1186/1471-2334-13-S1-O5

Cite this article as: Cambrea et al: Can HIV infection during pregnancy cause an intrauterine growth restriction? BMC Infectious Diseases 2013 13(Suppl 1):05.

* Correspondence: claudia_cambrea@hotmail.com

${ }^{1}$ Clinical Infectious Diseases Hospital of Constanța, Romania

Full list of author information is available at the end of the article 